\title{
Comunicación

\section{Aro Tolbukhin y la superposición de los niveles ficcionales}

Aro Tolbukhin and the overlapping of ficcional levels

El presente artículo trabaja con el atípico filme Aro Tolbukhin. Dins la Ment de l'assassí (2002) de Agustí Villaronga, Lydia Zimmermann e Isaac P. Racine, donde destaca la desarticulación de los códigos del género documental para evidenciar la imposibilidad de referirse a lo real sin aludir a la ficción. Enunciadas desde diversas perspectivas en superposición desde usos no cronológicos que dan cuenta de una nueva manera de narrar dentro del panorama del cine español, estos niveles ficcionales se confunden entre sí en función de una óptica donde lo idílico se combina con lo atroz.

PALABRAS CLAVE: Género, falso documental, realidad, documental, ficción.
This article works with the atypical film Aro Tolbukhin: Dins la Ment de l'assassí (2002) directed by Agustí Villaronga, Lydia Zimmermann and Isaac P. Racine. In light of an event presented as historical, and constructed according to the codes of the documentary genre conventions, this analysis addresses the complex articulation among different fictional layers. Enunciated from diverse superimposed perspectives from non-chronological uses that manifest a new narrative mode within the outlook of Spanish cinema, these fictional levels entangle with each other based on a lens where the idyllic combines with the atrocious.

KEY WORDS: Genre, false documentary, reality, documentary, fiction.

1 Universidad de Costa Rica, Costa Rica.

Correo electrónico: csanabriacr@yahoo.com

San Pedro de Montes de Oca s/n, C.P. 11501-2060; San José, Costa Rica. 


\section{INTRODUCCIÓN}

Ha de ser un caso atípico que en la última década del cine español, pocos años después agravada por la recesión económica del país, logren gestarse proyectos que superen el modelo hegemónico. Es el caso de filmes que entrañan la problematización en torno a la fenomenología entre los géneros documental y de ficción. En ese panorama resalta la película Aro Tolbukhin: Dins la Ment de l'asasassí (2002), dirigida conjuntamente por el consagrado Agustí Villaronga, la debutante Lydia Zimmermann y el diseñador gráfico y publicista Isaac P. Racine. Con más premios en México que en España, el filme se compone de un complejo entretejido de diferentes segmentos (narrativos, temporales) articulados entre sí, lo que dificulta el discernimiento -cuya legitimidad precisamente se pone en duda- en la representación de lo real, lo fingido y lo ficticio. Conociendo la prominente trayectoria experimental y provocadora de Villaronga, que no se permitiría nada que no fuera la evidencia de la desconfianza creciente en torno a la indicialidad de la imagen, Aro Tolbukhin ... se lleva al extremo de asentar la única certeza en la suspicacia del espectador.

Con base en ello, el análisis propuesto del filme se focaliza en el nivel textual, es decir, en la construcción de los mecanismos internos de la narración cinematográfica a partir del empleo de distintos códigos del género documental -esto es, de la necesaria interposición de criterios en última instancia subjetivos en la construcción de una imagen que rechaza su aceptada transparencia y cuya articulación de niveles en el flujo narrativo resalta su misma complejidad-. Desde esta estratagema, la película termina afirmando la primacía de la ficción de alta referencialidad convencional en un proceso sobre el que interesa demostrar las fisuras que se cuelan por sus niveles de narración.

\section{EL ROLLO ENCONTRADO}

Según su inicio, resulta determinante el hallazgo, en el estudio francés TSR, de unas latas que contienen rollos de filmes próximos a la desaparición. La voz en over de Lydia Zimmermann explica que en 1981 este 
material había sido parte de un proyecto original de entrevistas a condenados a muerte para una serie documental de cinco capítulos llamada Trois Jours Dans la Baleine. En esas primeras imágenes la realizadora Zimmermann aparecía junto a su colega francés Yves Keetman mientras se internaban en los pasadizos del estudio hasta finalmente acceder a una especie de sótano. Es una escena que remite a la convención del manuscrito encontrado (que en la literatura histórica recae en el tema del códice hallado tras arduas pesquisas, aquí se traslada a las latas de rollos de películas archivadas en formato super-8) como el procedimiento de "legitimación del origen” (García Martínez, 2007, p. 316). En la creación narrativa -literaria, cinematográfica- la utilización de este tópico otorga verosimilitud a lo narrado, para fingir "el hallazgo de un manuscrito que, incluso, ha podido ser perseguido con notorio ahínco" (Gómez Redondo, 1994, p. 164). Ese empeño se refuerza cuando Keetman expresa, con su ¿elaborado?, ¿deliberado?, incorrecto castellano: “Cada vez que bajo aquí estoy muy conmovido, es como bajar a unas catacumbas con nuestras latas, como cadáveres olvidados ... angelitos dormidos con ganas de revivir esperando nada más la luz de un proyector, ¿no?’. Y de inmediato afirma, casi a modo de sutil advertencia dirigida menos a su interlocutora que a los espectadores: "Muchas de estas latas acabarán dentro de poco a la basura ya que hubierais llegado un par de años más tarde no hubierais encontrado lo que venís buscando que está aquí".

El proyecto español afirma proponerse la recuperación y reelaboración de estas imágenes vinculadas con la realidad (supuestamente histórica) guatemalteca. La historia está construida desde las convenciones del documental, para lo cual intenta convencer al espectador que está ante un hecho verídico y cuya asistencia se torna un acto privilegiado: el rescate de un material de incalculable valor. La utilización rigurosa de las fuentes primarias del rollo encontrado y la evidencia de la presencia autoral (parcial) de la dirección (visibilizada únicamente en la también actriz Zimmermann) contribuyen a dar fe de las estrategias de garantía histórica. ${ }^{2}$

2 Como afirma García Gual (2002) en referencia a la narrativa en general, “(n)ada parece ser más de fiar, en una primera impresión, que el relato 


\section{DISPERSIÓN SIMULADA}

El resultado que se muestra bajo el título Aro Tolbukhin... es una mixtificación audiovisual aparentemente desorganizada, de una manifiesta atipicidad en rodajes (que no necesariamente locaciones) distantes e insólitos por inconexos entre sí (Guatemala, Francia y Hungría). Se tendría entonces, para empezar, una heterogeneidad de materiales de formatos dispersos, que van desde el super- 8 , el $16 \mathrm{~mm}$, el $35 \mathrm{~mm}$, el blanco y negro -bajo diversas coloraciones y texturas que oscilan entre una estética desteñida, con grano en la construcción del pasado cercano (los años ochenta) hasta la nitidez más evocadora del blanco y negro para aludir al pasado más lejano (mediados del siglo XX)-, pasando por soportes de video, reportajes televisivos, foto fija de imágenes de archivo, recortes de prensa ... (y voces) entrevistas, testimonios, enunciadas desde distintos niveles temporales. Destaca la notable fragmentación que realza el trabajo de montaje como parte estructural de la convención genérica del discurso documental, el cual "colisiona ... con el ideal de representar el mundo sin mediaciones” (Weinrichter, 2005, p. 61).

En una primera instancia, las imágenes del documento original que motivan la construcción del filme están referidas a lo que parece que habría tenido relación con el polémico individuo que le da título a la película. Éste, con sus paradójicas y contradictorias declaraciones, se autopresenta coincidentemente rodeado de una ausencia total de certezas. A esta variedad de perfiles se añaden los testimonios de otros individuos que se incluyen tanto en la fuente original (el material del rollo encontrado) como de los que aparecen en las imágenes 20 años después de su ejecución: en la onomástica (Hans Wyss/Aro Tolbukhin), en las apócrifas nacionalidades (alemana/húngara), en los nombres de sus padres, en la edad, en las declaraciones sobre el número de víctimas, en los oportunos silencios de él mismo sobre los crímenes que se atribuye.

narrado en primera persona. No parece haber, al pronto, mejor recomendación para cualquier pretensión de veracidad que la afirmación de alguien que ha vivido como actor principal o testigo inmediato los mismos sucesos narrados" (p. 30). 


\section{LAS FISURAS DE LA CONVENCIÓN DOCUMENTAL:}

\section{LAS RECREACIONES DRAMATIZADAS}

En la construcción de un hecho histórico, Nichols (1997) plantea que los documentales arriesgan su credibilidad porque se produce una ruptura del nexo indicativo entre imagen y referente histórico, es decir, se propone la existencia de una elaboración más distanciada de lo que en principio tuvo lugar. Considerando entonces la aparente y abundante dispersión de fuentes históricas, una de las formas de pretender su organización consiste en el empleo más depurado e intercalado de la dramatización. Se trata de una categoría híbrida de origen televisivo (Corner citado en Newcomb, 1997) que remite - de nuevo- a los dos niveles ontológicos: realidad y ficción.

En principio, el trabajo fílmico de reconstitución de un proyecto archivado dejaría mostrado, independientemente de su carácter apócrifo, su necesaria concomitancia con la ficción: si todas las entrevistas y testimonios de base se abocaban a presentar a un sujeto teóricamente mostrado como impenetrable, la derivación lógica es que sus directores no habrían tenido otro subterfugio más que acogerse a la recreación o simulación dramática, mecanismo habitual en el documental.

Estos dos tipos de fragmentos (las imágenes del rollo encontrado y la recreación a la que darían pie después) parten de una visión subjetiva y doblemente mediada: la fuente de enunciación que permite iniciar la reconstrucción dramática apegada a los testimonios -es decir, provisionalmente surgidas (sugeridas)- para en cierto punto tomar distancia y adquirir una focalización distanciada, ajena -más que omnisciente-, relativa a las propias y subjetivas elucubraciones de los directores/guionistas. Es como si el documento fílmico se hubiera valido del necesario proceso de ficcionalización para colar, por los intersticios de la convención documental, la evidencia de la aplastante opacidad de lo real. ${ }^{3}$ Así, la

3 Ante la pregunta de cómo separar lo verdadero de lo falso, Josep Maria Català plantea: "Estamos en las antípodas de las operaciones de aquel nuevo periodismo que bebía en las fuentes de la realidad para producir ficciones: aquí se parte en busca del manantial de la ficción para con sus aguas imprecisas producir realidades" (Català, Cerdán \& Torreiro, 2001, p. 35). 
inclusión del elemento dramático -el contraste de los segmentos del material originario (la entrevista y el resto de las imágenes en fotografías y super-8) con las recreaciones dramáticas (en formato televisivo)-permite legitimar la categoría de verdad (bajo la forma teóricamente documental) desde donde se articula la narración fílmica. La segunda entrevista a Tolbukhin supone un abandono del interés de inscribir lo real a partir de la articulación combinada de técnicas y formatos televisivos que, para Corner, dotan de creatividad al documental (citado en Newcomb, 1997). Lo que subyace tras todo ello no es pues sino la premisa de que lo representado ante la cámara viene a ser una información incompleta.

\section{LAS POSIBILIDADES REPRESENTATIVAS}

Un primer fragmento que escapa a las convenciones de la narración clásica del documental elabora una escena de recreación dramática, en la cual la realidad suele construirse con la intervención de sujetos que se representan a sí mismos o bien con actores profesionales, ${ }^{4}$ lo que induce a pensar este formato en clave de ficción narrativa (Barroso citado en Ortega, 2005, p. 175). El desdoblamiento interpretativo en Aro Tolbukhin ... constituye una muestra parcial más de su complejidad estilís-

4 El empleo de abundantes y diversas fuentes como puntos de vista (típico de las propuestas relativistas) sobre un mismo sujeto es un recurso estilístico del fake, que ya había llevado a cabo Orson Welles en F for Fake (1973) -las entrevistas a los supuestos falsificadores Elmyr d'Orty y Clifford Irving- y poco después Woody Allen en Zelig (1983) que incluía, entre otros, a Susan Sontag, Bruno Bettelheim o Saul Bellow. En general, la presencia de estos actores sociales -los cuales, según Josep Maria Català, "se prestan a representar papeles falsos, a colaborar con el engaño general con discursos espurios que ellos suscriben gozosos a favor de la verosimilitud de un simulacro" (Catalá, Cerdán \& Torreiro, 2001, p. 33)- evidencia una esquizofrenia moral o un problema ético que exoneraría (aunque solo parcialmente) a Aro Tolbukhin... por cuanto pivota en actores profesionales y espontáneos. Por eso es un filme que muestra las fisuras de lo real haciendo uso de recursos convencionales del género -el documental-, como las recreaciones o simulaciones dramáticas. 
tica pues, a pesar de la consonancia física, resulta evidente la presencia de otro distinto al original: Daniel Giménez Cacho, un conocido actor mexicano del cine y la televisión -que, para complicar más las cosas, simula acento español- cuya aparición se ve justificada en la diégesis por la necesidad de interpretar la última (y alucinada) entrevista.

En las interpretaciones dramáticas quedaría justificada la utilización de dobles profesionales para la recreación de los testimonios presentados como originales. Pero el arte no necesita de justificación y, lejos de resolver, su intermediación se convierte en una espiral que recurre en un segundo grado al registro de la entrevista de esos actores que estarían a su vez representando a los presumibles personajes originales. Todo ello reniega de la verosimilitud postulada inicialmente a partir de aquellos mecanismos: aparte de lo ominoso que alberga el original desdoblado como manifestación del impulso de repetición (Freud, 1976), las entrevistas recreadas arrojan mayor confusión ex profeso.

Un procedimiento semejante se intenta trasladar con la original entrevistadora, de cuya herencia Keetman había hecho una rápida y marginal alusión al inicio. Su interpretación viene desempeñada por una actriz que representa estar fuera del ámbito de la ficción, perteneciente al ámbito de la creación documental -la codirectora Zimmermann-, pero que se integra a la historia al encarnar un doble papel: a la hija que busca dar término al proyecto inconcluso de su madre (Lise August) a la que también interpreta -lo que permite insertar, como apunta Cerdán, elementos de una realidad anterior y al mismo tiempo hacer referencia a una posibilidad de objetividad documental (citado en Ortega, 2005, p. 128)-. Semejante a este desdoblamiento procede la escisión del otro personaje femenino, la hermana dominica Carme Curt, en dos actrices para el pasado recreado en la Misión (Carmen Beato) y el presente actual de la entrevista (Margarita Ferrán).

Estos desdoblamientos resultan turbadores de acuerdo con las convenciones del género documental porque atestiguan "una fisura entre el texto y la vida a la que hace referencia" (Nichols, 1997, p. 312). Desde luego que para la dirección conjunta eso no es un problema: antes bien, la utilización de -hasta el momento- dos intérpretes protagónicos diferentes constata la condición paradójica, desdoblada de la narración, que se unen a las múltiples voces. De hecho es un mecanismo intercalado a 
lo largo de todo el relato que le dota de una calidad de aspecto distinto, a la manera de un complejo entramado de envolturas de capas de diferente ontología o apariencia.

\section{PIRÓMANO ASESINO}

Al afán verosimilizante se suma entonces la inserción de segmentos respecto del material presentado como original, en concreto, las recreaciones dramáticas, que suponen una mayor elaboración imaginativa, dependiente siempre del discurso presentado como fáctico. Habría en todo esto una intención verosimilizadora de ilustrar visualmente los diferentes testimonios emitidos desde la manifiesta legitimidad (occidental) reconocida - un cura (cuya autoridad emana de la sotana y el crucifijo), una ex religiosa (también delegada de la fe), un abogado defensor (apoderado de la ley y avalado por el conocimiento que ostenta en los títulos de su despacho), la prensa (sensacionalista y representante de la verdad incluso cuando califique al acusado de "pirómano asesino")-, más la entrevista a testigos presenciales, de acuerdo con lo que corresponde a las técnicas documentales. Así pues, se tiene una especie de collage polifónico que le da un seguimiento lógico a la historia echada a andar y en un principio dependiente de los flujos discursivos: la llegada de Tolbukhin a la Misión, su enfermedad, los cuidados de la hermana Carme.

Hasta aquí serían, como se ha dicho, sucesos apegados a los testimonios narrados que no dejan de suponer una segunda mediación lograda por la visualización fílmica (a lo que habría de sumársele esa paulatina y casi inadvertida construcción ficcional de los acontecimientos que los depura y estiliza cada vez más). ${ }^{5} \mathrm{~A}$ pesar de la aparente fragmentación

5 Una vez asentado Tolbukhin en la Misión, la recreación fílmica -que se articula por los testimonios verbales-, adquiere independencia, toma una extraña, acaso inquietante, distancia y provisionalmente se olvida de las voces testimoniales, asumiendo casi una perspectiva omnisciente. Esa fuente de enunciación continúa la narración con la llegada, el parto y muerte de una indígena acogida en la Misión y la consiguiente adopción putativa del bebé Kuti -cuya suerte venía ya dictada en su nombre: salvado por el fuego pero no por las aguas-. "El seu nom de Kuti s'ho va posar ell. És un nom que en 
del episodio que surge de todos los testimonios, esta recreación dramática tiene el empeño de construirse bajo los códigos del documental a través de una elaborada creación de acuerdo con la instancia narrativa organizadora que habrá de revelarse como tal: una construcción altamente subjetivizada por la mediación de sus capas que implican la presencia de la ficción.

\section{EL MONSTRUO ORIGINARIO}

El otro fragmento, formal y técnicamente más distanciado aún del resto del filme, se aboca a visualizar una nueva recreación dramática que se justificaría, según Keetman, con el hecho de que el entrevistado se negó a filmar y solo se grabó en audio. Con esta segunda entrevista se da pie a una extensa porción del largometraje que se termina desarrollando durante poco más de un tercio y que sería el verdadero adentramiento en la mente del asesino. Al estilo de las imposiciones cervantinas, este segmento ostenta una categoría estructural en sí misma cerrada: su propia introducción -las condiciones del nacimiento del protagonista-, iniciada con escasa anterioridad, hasta su partida de la casa paterna, sin cortes tajantes ni juegos con el tiempo ni con la enunciación como el resto anterior. Su problematicidad se acentúa a raíz del estatuto ontológico y ambiguo que había sido previamente sentado, donde bien puede concebirse como un segmento independiente, autónomo, ajeno y si se quiere casi prescindible a lo anteriormente mostrado -lo cual tampoco es inconsistente con la idea de mediometraje para televisión que se pensó en un inicio (Pedraza, 2007, p. 83)-, aunque también puede verse como una recreación dramatizada que ilustra en imágenes -o contiene como en una estructura de mise en abyme al discurso de Tolbukhin- el discurso de la nana húngara, Slamár Yulané (cuyo testimonio, además del tiempo y la memoria, está media-

idioma ketchi-e vol dir "salvat del foc", explica la ex monja Carme Curt. Formalmente el dato adquiere importancia porque a estas alturas el espectador ha recibido dosificadamente la información que le permite establecer la relación de Tolbukhin con el fuego - que se solidificará en la última parte, la referida a su infancia- y por tanto sospechar de la existencia de una elaboración artificiosa, como parte de los mecanismos ficcionales del docudrama. 
tizado por la traducción -traduttore traditore-). La razón de ser de tan complejo tejido parecía consistir en mostrar (aunque nunca justificar) que la conducta del personaje en referencia expresa al pasado más lejano, al estado probablemente más vulnerable de todos: la infancia.

Tampoco se trata de un pasaje menos truculento a pesar de que está referido a un asunto aparentemente menor, aunque de excepcional fragilidad. Pone en boca de Giménez Cacho que en su infancia nunca hubo contacto con la madre más que a través de las fotos y las notas que el lejano padre les leía a él y a Selma, su hermana gemela. El sentido dramático se refuerza con la música del piano que escuchaban desde su habitación y un fundido a negro da paso a unos didascálicos, los cuales, desde una caligrafía que evoca la habitual del cine mudo, rezan: El vestido deshabitado. Este nuevo inserto acusa una mayor violencia respecto de la narración antecedente porque supone una ruptura abrupta con la continuidad anterior desde varios aspectos. En primer lugar, no solo porque mantiene cierta consistencia en sí mismo en cuanto a tratamiento de imagen (textura, formato, definición y coloración), ni tampoco porque fuera el resultado de una menor mediatización, como se acaba de plantear. Sobre todo, su disonancia radica en el contraste respecto del estilo marcadamente más fantasioso que el apego a las convenciones documentales de la narración precedente. Si en el fragmento anterior el ingenio se antojaba creciente, aquí resulta tan desbordante que solo se explica recurriendo a la ficción cuyo tono semeja al de un mustio cuento infantil, con el que contrasta radicalmente la investigación convencionalmente documental del inicio.

Se fija aquí el desarrollo de una dimensión más íntima sobre los primeros años del criminal convertido en personaje que narra una historia desde lo que en principio se presume los recuerdos de su hogar, que es donde reside la esencia de lo unheimlich, es decir, la negación de lo que en referencia a la vida psíquica tiene que ver con lo familiar (heimlich) vuelto extraño en su proceso de represión (Freud, 1976, p. 46), como los verdaderos motivos de la ausencia materna, de posibilidades traumáticas en su descubrimiento que justifican la mentira del padre y acucian la inventiva de los niños. Esta sección inicia con una narración en over que empieza a ser contada precisamente a partir del final de los relatos clásicos, con la feliz historia del matrimonio de los progenito- 
res en una mansión rural. Su felicidad sin embargo se desmorona tras el nacimiento de los hijos gemelos -nuevo desdoblamiento, pero esta vez no performativo, sino argumental, en función de otra variable de lo siniestro como retorno de lo semejante y vinculado con la vida psíquica infantil (Freud, 1976)-, mientras por la cámara se suceden una serie de fotografías y personajes húngaros pretendidamente de la época: según Pedraza (2007), estas fotografías de archivo - de familias húngaras-que huyen en 1956 de la invasión soviética constituyen el único y verdadero material documental en todo el filme.

Uno de los aspectos que a ese respecto resultan más sugestivos en lo referente a las convenciones de semejanza con la realidad del documental es que los actores que encarnan al protagonista en esta primera etapa -la niñez y pubertad-guardan cierto parecido físico entre sí, pero no quienes interpretan al personaje en su adultez en Guatemala, como si el salto temporal adquiriera una determinación tal que se visibilizara en la constitución física. Es decir, la continuidad en el nivel de semejanza fisonómica en relación con quienes representan al posterior condenado a muerte se debilita notablemente -Xhévdet Bajrat y Daniel Giménez Cacho (véase Figura 1) que, pese a no compartir siquiera nacionalidad (el primero croata y el segundo mexicano), son parangonables por la referida homogeneidad en la estampa (escaso pelo, desaliño en el vestuario y afeitado)-. Este hecho sutil lleva a suponer el resquebrajamiento del lazo de conexión de los personajes entre los dos momentos mostrados: la convulsión de mediados del siglo XX en Europa Oriental

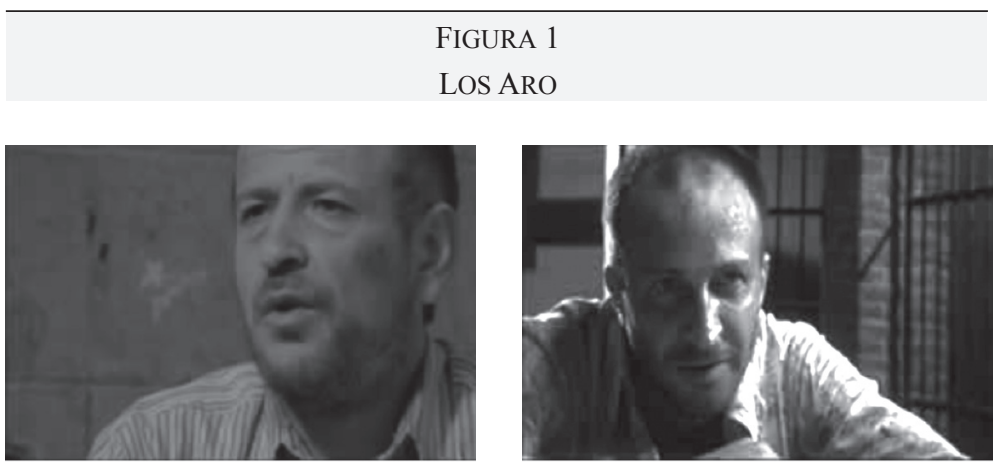


y en los inicios de la década de los ochenta en la no menos violenta América Central. Pero también una vez más en el nivel estructural se refuerza la posibilidad ya mencionada de que éste pudiera ser un segmento divisible (no innecesario) de la historia del asesino (el pasaje infantil y adolescente en su tierra natal).

De modo que si el relato se toma como ilustración del testimonio del personaje interpretado por Giménez Cacho, la organización fílmica parecería proponer la existencia de un suceso decisivo en la vida del adolescente Tolbukhin, de donde se deducirían los sangrientos crímenes de Guatemala, con la relación incestuosa de los hermanos adolescentes en Hungría. Sin desdecir las posibilidades ominosas del doble, cabe destacar también que el tema del amor del hermano y la hermana es simbólico en el Romanticismo: con base en la idea de que los opuestos masculino y femenino participaban de una fuente genética común, se les representaba a menudo como la personificación de una unión incestuosa (Abrams, 1962). Sobre esa indirecta base, el relato está contado desde una alta carga de sensibilidad en la textura de las formas, casi etéreas, como en un sueño. No se destilan reprobaciones o moralismos: la historia corre con fluidez -como correspondía a la vivencia de dos jóvenes unidos en la soledad-por esa instancia de enunciación que se delega y difumina: Tolbukhin, Yulané, una voz femenina, un narrador omnisciente ... Incluso se permite recursos como la evocación de personajes del presente y del pasado en un mismo plano (general), en el momento en que una Yulané ya mayor se entrecruza, en las visitas al cementerio -que estaban siendo relatadas y recreadas en ese mismo momento-, con una mujer y dos niños, como entremezclando los tiempos (véase Figura 2). Le sigue un cambio de plano, esta vez más cerrado, donde la cámara se detiene algunos segundos en la lápida que reza los nombres de la madre, "Zsófia Gaál (1916-1940)", y poco más abajo, "Selma Tolbukhin” (1940-1956) (véase Figura 3). Visto así, se está ante un recurso poco realista, más narrativo ${ }^{6}-\mathrm{y}$ en ese

6 Que, en calidad puramente documental estaría más aproximado a la modalidad poética de Nichols (2001): "The poetic mode began in tandem with modernism as a way of representing reality in terms of a series of fragments, subjective impressions, incoherent acts, and loose associations" (p. 103). "El 

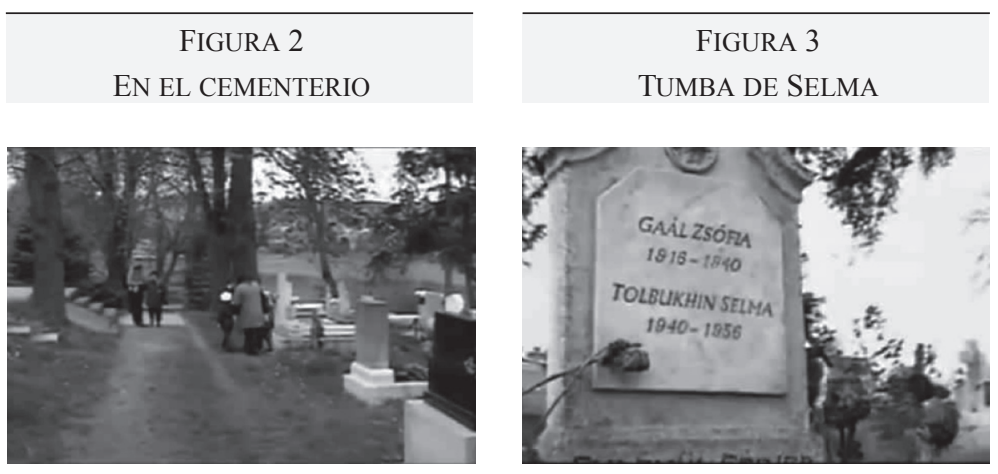

sentido, contrastante con la aplicación de convenciones documentales subrayadas al inicio- que permite anticipar la prematura muerte de la hermana a través de la condensación de la ambigüedad del presente de la narración y el pasado de la evocación. Es así como durante la adolescencia, ante una bellísima pero angustiante escena sexual que Yulané contempla, decide alertar al padre, el cual organiza una fiesta de presentación en sociedad para su hija. Es cuando, en medio del alegre festejo, tiene lugar el trágico accidente con su vestido, que también quedará deshabitado. Sin embargo, hasta la manera de escenificarlo resulta de una delicadeza fotográfica de primoroso cuidado que contrasta con la violencia de su horrorizada visión: se asume la perspectiva de un anónimo niño que se ha apartado de la fiesta para darse un atracón con un postre previsiblemente de nata. Entonces se interrumpe el sonido de la música por los gritos de pánico que dan paso inmediato, desde un segundo piso, a una figura en contrapicada que arde en llamas -metáfora de la pasión incestuosa (Pedraza, 2007, p. 30)- y que baja por las escaleras para abalanzarse a la salida, cuyas puertas se abren trágicamente en comunión desesperada (véase Figura 4). Grabada esta imagen en la retina de su hermano, la historia parece suscitar explicaciones o quizás abrir eventuales atenuantes. Pero ante la pregunta de la joven

modo poético comenzó unido al modernismo como una forma de representación de la realidad en términos de una serie de fragmentos, impresiones subjetivas, actos incoherentes y asociaciones libres" (traducción propia). 


\section{FIGURA 4}

LA NOVIA EN LLAMAS

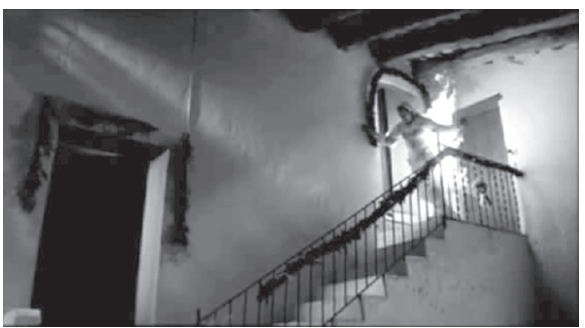

August -la razón de su relato-, el personaje-narrador, irónico, termina diciendo que su interés no buscaba exceder su entretención. De este modo, la incorporación de este segmento cuestiona el recurso de la asociación narrativa y el psicologismo reduccionista de la complejidad psíquica. No cabe la posibilidad ni siquiera en el arte de explicación para lo aberrante.

Aparte de la atmósfera de irrealidad, el relato contrasta notablemente con el flujo de imágenes anteriores. Cualquier concesión o afán a la verosimilitud ha quedado definitivamente cancelado, el cual sin embargo se recupera tras el fundido en negro con que cierra el cuento y que precede a los nombres sin más de los intérpretes con el acompañamiento de la banda sonora, la canción de cuna en húngaro, en una inevitable remisión a la niñez del protagonista. No obstante, el espectador no alcanza certeza de a cuál versión corresponde esta pieza: bien podría ser la inventada por los hermanos y que choca con la poeticidad de la historia infantil por cuanto, incluso como juego, la letra original es modificada por otra que Giménez Cacho traduce (o traiciona) como "mi puta madre se folló a un obispo y en el cielo se comieron un piano dos niños". De darle crédito a sus palabras, la idealización de la madre, su falta manifiesta como ausencia incomprensible, casi inmanejable, terminaría esfumándose -lo cual vendría a reforzar, de nuevo, cualquier intento que pudiera explicar el proceder del condenado-. Si se recuerda lo dicho por Yulané sobre la marcada ausencia de afinación de voz del pequeño, el espectador puede suponer que está entonada por el mismo 
Giménez Cacho, a la que poco después se traslapa por la de un coro de anónimos niños en la otra posible versión, decididamente más angelical, que reviviría la que le cantaban a su madre y que hablaba -según, de nuevo, la traducción de Tolbukhin- del campo y de las flores, como corresponde a las piezas infantiles. O tal vez no: la expresión máxima de candor que claramente la producción cinematográfica de Villaronga se aboca a destruir a través de puericias truncadas, ${ }^{7}$ de orfandades literales o metafóricas -en otros filmes como El Mar (2000) o Pa Negre (2010)-, conduce a acentuar el tránsito de la manoseada inocencia infantil hacia la podredumbre humana.

El cierre da pie a que la ambigüedad del personaje principal, de los intérpretes, de la historia, de la enunciación, se termine volcando también al audio como forma de comprender todas las posibilidades de percepción de lo real -un documento como afirma Catalá, donde lo real se valora tanto como las propias imágenes (Català, Cerdán \& Torreiro, 2001, p. 41)-. Este final torna más avieso el filme básicamente por proximidad con la supuesta recreación de la infancia (vulnerable, ingenua) recurriendo al pasado de un sujeto desde su extraña historia familiar (unheimlich). De victimario terminaría convertido en víctima social tras haberse conocido una historia (que podría o no identificarse con su niñez) casi tan terrorífica como la de los crímenes posteriores, de sombras y fantasmas en una vieja casona, en última instancia, de soledad y fantasía tan caras a Villaronga. Pero además el abrupto cierre de irrupción de metraje real, presentado como de archivo, con la voz en over del supuesto abogado defensor al recordar el levantamiento del acta notarial, dota a las imágenes subsiguientes (del fusilamiento militar), a través del recurso típico del género documental -la reubicación o recontextualización (Weinrichter, 2005, p. 61)-, de un nuevo y denodado sentido -contrario a la pena de muerte- mediante una enunciación altamente perifrástica pero no menos efectiva a la idea del proyecto original.

7 Es un motivo del cine de Villaronga: los niños por distintas razones cercenados físicamente -sin dedo (el joven Aro), sin pierna (Rodrigo), sin mano (Núria de Pa Negre)- como alegoría de una mutilación interna. 


\section{EL MONTAJE LITERARIO}

La historia relatada desde el comienzo se desmorona al descubrirse -si es que se descubre- que el material de partida es tan ficcional como el episodio delirante de la infancia. De lo contrario, no pasa nada: también es posible resistir al engaño, sobre el que se asienta la credibilidad del espectador en la recepción narrativa, con lo que el filme está en capacidad de manejarse en varias dimensiones de recepción.

En todo caso, la forma es básica como parte de la construcción de la impostura: la imagen añejada y la utilización del formato super-8 dan cuenta del proceso de avejentamiento de la imagen del material encontrado, desgastado, decolorado y hasta rayado, sometido a un procedimiento consonante con el engaño hacia donde se conduce al espectador con casi tanta perversidad como entretención. Todo es parte de un montaje -más bien, la película enteramente es, lo mismo que se ha dicho de la de Orson Welles (1973), un filme montado (Farré, 2008)- que utiliza las herramientas convencionales del género al servicio de la ficción. ${ }^{8}$

La más abrumadora constatación podría verse también en la construcción del protagonista. En las imágenes originales aparecía retratado desde el artificio, con la solemnidad y hasta dignidad que cabe esperar en un condenado a muerte: miradas al vacío, preguntas sin responder, pausas altamente dramáticas, bocanadas al cigarrillo para acentuar su carácter enigmático. Al estar contenido en el rollo encontrado se disfraza a la entrevista de cierto valor histórico (verificable): son esas fisuras que permiten añadir insertos más elaborados (en otros planos diferentes de ficción) a partir de su contraste dramático, homólogo en cierto modo al método de trabajo de Walter Benjamin (2005) de montaje literario. Una de sus más preclaras exegetas, Susan Buck-Morrs (1995) sostenía al respecto que la yuxtaposición de fuentes da pie a que "la

8 Para construir un falso documental, que, como tal, es "un caso especial, por lo que tiene de deliberado, de ese eterno combate entre lo ficticio y lo real que se ha librado históricamente en el interior de la institución documental: presenta un relato inventado que, a diferencia del cine de ficción habitual, imita los códigos y convenciones cultivados por el cine documental" (Weinrichter citado en Torreiro \& Cerdán, 2005, p. 69). 
teoría surja de allí sin necesidad de ser insertada como interpretación" (p. 91). En efecto, la complejidad en la construcción y enunciación aquí se evidencia en la conformación de planos de primera entrada bastante distinguibles los cuales operan en función del personaje. Uno primero, como se dijo, aparente, referido a las circunstancias que interpreta Bajrat, figura como el auténtico -lo cual remite a un primer nivel de ficción- que da pie a otro definido por la actuación profesional de Giménez Cacho -en alusión a una segunda categoría de ficción-, y un tercero que concierne a la infancia y adolescencia del personaje en Hungría. Todos estos niveles están articulados desde una fuente de enunciación -encarnada en Keetman y Zimmermann- hipersituada y ajena, de un autoritarismo por cierto inconsistente con la cálida voz femenina en over que constituye la dimensión organizadora del relato que precede, selecciona y dirige la articulación de las distintas densidades ficcionales.

Como propone Cerdán, Aro Tolbukhin ... es una película puramente de ficción que trabaja con la aplicación cuidadosa de registros del género para hacer más próxima y creíble su historia antes que interrogar los límites del documental mismo (citado en Ortega, 2005). Al negarse entonces la posibilidad de transparencia se reafirma el de la ficción que, a través del uso lúdico, recurre a estrategias verosimilizantes como las convenciones solidificadas del discurso documental. ${ }^{9}$

\section{CIERRE}

La adopción de tan singular manera de construir un relato fílmico -cuya riqueza no está en la historia, en la anécdota, sino en la forma de narración, el entretejido- da cuenta de un juego con el contrato establecido entre el documental y el espectador que para Weinrichter (2005, pp. 61-73) parece fascinar o divertir más que a los documentalistas, a los cineastas, quienes han encontrado nuevas formas de expresión para saciar la necesidad de plasmar sus inquietudes personales desde tanteos de carácter más experimental.

9 Lo que, siguiendo a Català, reivindica, como lo hiciera Jean-Luc Godard en sus Histoire(s) du Cinema (1988), el género del fake como testimonio de gestualidades verdaderas (Català, Cerdán \& Torreiro, 2001). 
Se termina recurriendo a estrategias de verosimilitud del documental para manifestar su reflexividad, reivindicar elucubraciones surgidas a raíz del manejo de las convenciones solidificadas del registro en un intento de establecer una problematización estilística, como en una banda de Moebius, de las formas de representación de la realidad que siempre desembocan en algún grado de ficción. Aro Tolbukhin... asume las convenciones del cine documental que suponen las intenciones de transparencia implícitas en la indicialidad de la imagen para evidenciar las fisuras como necesidad de ser llenadas ("completar el trabajo inconcluso", según la voz en over de Zimmermann) primero a través de la inserción de dramatizaciones verosimilizantes para ilustrar o contener los testimonios que paulatina, imperceptiblemente desplazan otras elaboraciones que recurren a una mayor inventiva próxima a la alucinación, al desvarío. ${ }^{10}$ Con este filme Villaronga, Zimmermann y Racine parten del género del fake para postular la "capacidad de conocimiento que proporcionan las imágenes" (García Martínez, 2007, p. 307), su insuficiencia para explicar hechos insondables y menos aún referidos a la mente humana; por tanto, un desafío que se vierte en varios sentidos: a las convenciones del cine dominante y comercial y también a la credibilidad y a las predisposiciones del espectador centrada en la explicación imposible de las motivaciones de un insólito asesino en serie. La suspensión oscila o vacila durante los fragmentos dramatizados, enfrentados por proximidad con los supuestamente recuperados. Ni los unos ni los otros -en lo que termina ironizándose como una investigación aunque interrumpida, rigurosa y contrastada- arrojan claridad, sino confusión, vaguedad. Lo ominoso del protagonista termina tiñiendo también el resto de la historia, al filme mismo. El resultado es por tanto una espiral de ficcionalizaciones que conduce a la remisión del flujo hacia las imágenes consagradas como originales, sobrevaloradas por su revestimiento histórico, por su carácter de verdad, aunque caídas en la desgracia de la mentira que provechosamente se mantiene y se oculta todo el tiempo.

10 De ahí la alta fragmentación del discurso fílmico remarcada por el propio montaje, básico en la construcción del cine documental y su "empresa misma de representar el mundo sin mediaciones" (Weinrichter citado en Torreiro \& Cerdán, 2005, p. 69). 


\section{Bibliografia}

Abrams, M. H. (1962). El espejo y la lámpara. Argentina: Nova.

Allen, W. (Director). (1983). Zelig [Película]. EE.UU.: Warner.

Benjamin, W. (2005). El libro de los pasajes. Madrid, España: Akal.

Braunstein, N. (1981). A medio siglo de El malestar en la cultura de Sigmund Freud. México: Siglo XXI.

Buck-Morrs, S. (1995). Dialéctica de la mirada. Walter Benjamin y el proyecto de los pasajes. Madrid, España: Visor.

Català, J. M., Cerdán, J. \& Torreiro, C. (Coords.). (2001). Imagen, memoria y fascinación. Notas sobre el documental en España. Madrid, España: Ocho y medio.

Farré, S. (2008). Sobre el mágico engaño del arte. Miradas de cine. Recuperado el 14 de septiembre de 2011 de http://www.miradas. net/0204/estudios/2002/08_owelles/fraude.html.

Freud, S. (1976). Lo siniestro. Argentina: López Crespo.

García Gual, C. (2002). Apología de la novela histórica y otros ensayos. Barcelona, España: Península.

García Martínez, A. N. (2007). La traición de las imágenes: mecanismos y estrategias retóricas de la falsificación documental. Zer, 22, 301-322.

Godard, J. L. (Director). (1988). Histoire(s) du cinéma [Película]. Francia: Gaumont.

Gómez Redondo, F. (1994). El lenguaje literario. Teoría y práctica. México: EDAF.

Newcomb, H. (Ed.). (1997). The Critical View. Nueva York, EE.UU.: Oxford University Press.

Nichols, B. (1997). La representación de la realidad. Cuestiones y conceptos sobre el documental. Barcelona, España: Paidós.

Nichols, B. (2001). Introduction to Documentary. Bloomington, IN, EE.UU.: Indiana University Press.

Ortega, M. L. (Coord.). (2005). Nada es lo que parece. Falsos documentales, hibridaciones y mestizajes del documental en España. Madrid, España: Ocho y medio.

Pedraza, P. (2007). Agustí Villaronga. Madrid, España: Akal.

Sontag, S. (2005). Contra la interpretación. Buenos Aires, Argentina: Alfaguara. 
Torreiro, C. \& Cerdán, J. (Eds.). (2005). Documental y vanguardia. Madrid, España: Cátedra.

Villaronga, A. (Director). (2000). El mar [Película]. España: Massa D'or Produccions.

Villaronga, A. (Director). (2010). Pa negre (Pan negro) [Película]. España: Massa D'or produccions/Televisió de Catalunya/Televisión Española.

Weinrichter, A. (2005). Desvios de lo real. El cine de no ficción. Madrid, España: T\&B.

Welles, O. (Director). (1973). F for Fake (Fraude) [Película]. EE.UU.: Janus Film/SACI.

Ficha técnica

Aro Tolbukhin. Dins la ment de l'assassí, 2002

Directores: Isaac P. Racine Guión: Isaac P. Racine

Lydia Zimmermann Lydia Zimmermann

Agustí Villaronga Agustí Villaronga

Producción: Oberón Cinematográfica/Altavista Films/Canal+ España/ Lestes Films/Televisión Española (TVE)/TVC/Ibermedia

Ayudante

de dirección: Álvaro Curiel

Fotografía: Guillermo Granillo

Montaje: Ernest Blasi

Vestuario: Lourdes Del Valle, Antònia Marqués

Sonido: Albert Manera

Música: José Manuel Pagán

Reparto: Daniel Giménez Cacho (Aro adulto), Xhévdet Bajrat (Aro adulto), Carmen Beato (hermana Carmen), Margarita Ferrán (hermana Carmen), Zóltán Józan (Aro joven), Mariona Castillo (Selma joven), Aram González (Aro niño), Eva Fortea (Selma niña), Jesús Ramos (cura), Lydia Zimmermann (periodista, Lise Agust)

Duración: 95 min 


\section{Sinopsis}

En 1981 se detiene a Aro Tolbukhin, acusado de quemar vivas a siete personas en la Misión del Divino Redentor en Guatemala. Él mismo confiesa también haber asesinado y calcinado los cadáveres de otras cinco mujeres, así como a otras 17 embarazadas durante los 15 años en que trabajó como marino mercante. La investigación judicial revela, no obstante, profundas grietas y contradicciones en la declaración inculpatoria de Tolbukhin, que fue condenado a muerte. El caso es conocido por dos documentalistas franceses que habían trabajado para un proyecto en contra de la pena de muerte que queda inconcluso y el material archivado. El filme empieza desde esa intención actual que vuelve a distintos niveles temporales del pasado retrotrayéndose a la grabación del condenado antes de su ejecución. Integra bajo testimonios de testigos diversos o del mismo asesino confeso una serie de recuerdos traumáticos o invenciones alucinadas para recrear el entonces pasado reciente (su llegada a la misión guatemalteca) y el pasado más remoto (la infancia en su Hungría natal). Estas intervenciones a modo de entrevista componen el relato de búsqueda de explicación de lo que al final queda revelado como un proyecto no solo inconcluso sino imposible: las motivaciones de su conducta.

Fecha de recepción: 04/10/12. Aceptación: 18/12/12. 